\title{
Auctions in Steel Industry
}

\author{
Borja Ena, Javier Puente, Alberto Gomez*, Paolo Priore \\ Administración de Empresas \\ University of Oviedo \\ Gijon, Spain \\ albertogomez@uniovi.es
}

\begin{abstract}
The paper analyzes the literature regarding the auctions of products in the context of the steel sector with three objectives: to identify its determining factors, decide the appropriate method of auctioning in that context and investigate the need to group products in homogeneous lots before the auction. For this, after exposing the current method developed in this type of auction, the following are analyzed: the possible types to be followed, their performance, the main factors of human behavior that may affect them, the factors for the proper design of online auctions and the need to group the products in homogeneous lots to optimize the auction. The consulted literature reveals the suitability of homogeneous groupings prior to the auction and proposes a new model for the on-line auction of iron and steel products.
\end{abstract}

\section{Keywords-Auctions; Steel; On-line auctions}

\section{INTRODUCTION}

Weekly, a large number of "non-prime" steel products from several plants of a European steel company are sold online through an auction mechanism. Prior to the auction, the products subject to the auction must be grouped into lots according to a series of characteristics and restrictions. Performing this grouping is a complex and key task, given its great impact on the final bid price of each lot (due to the intrinsic value of the grouping made and the attractiveness of the lot for the bidders).

This paper studies the problem in depth to determine both the characteristics to be considered in the optimal grouping of products and the complete auction process and its influencing factors. The most relevant studies carried out to date for the type of auction that is addressed in this paper (online, closed first price and simultaneous bid for several products) allow us to analyze if the auction method used is the ideal one and propose possible alternatives for the sale of "non prime" products.

The rest of the article is organized as follows. In section 2 , the problem to be solved is described and the current process of sale by auction of "non-prime" flat products is exposed in detail. In section 3 , an exhaustive bibliographic review is made about the type of auctions. Section 4 describes the factors to consider when designing an online auction. Section 5 includes a study on the suitability of carrying out product groupings prior to the auction. Finally, in section 6, the conclusions obtained are listed and recommendations are proposed on the model of auctions to be used for the sale of products in the steel sector.

\section{PROBLEM DESCRIPTION}

In this section, a description of the problem to be solved is presented, exposing the auction process of "non-prime" flat products, the volumes sold with this process and the importance of grouping the products in batches before their auction, detailing the restrictions to carry out the grouping and the requirements to be met by the proposed solution.

The steel sector is one of the main pillars of the world economy. Steel is the cornerstone of other sectors such as construction, the automobile, transport, energy, food, water, tools and machinery. The main advantages of steel are its excellent mechanical and structural properties (cold and hot moldable, weldable, hard and corrosion resistant) together with a relatively inexpensive manufacturing process compared to other materials (the energy required to extract iron from the ore it is $25 \%$ less than that required for aluminum). The steel is respectful with the environment since it is $100 \%$ recoverable due to its magnetic properties, and $100 \%$ recyclable [1]. In addition, it is obtained from a mineral that has high availability, since iron represents $5.6 \%$ of the earth's crust, and there are mines distributed throughout the world. The final characteristics of the material depend on the chemical properties of the steel grade: currently they are developed around 2000 degrees of different steel [2], depending on the final characteristics of the product.

The different steel products are classified into two large groups: flat and long. The flat products include slabs, coil (hot, cold, galvanized), tinplate and thick plate. These products are mainly used in the sectors of the automobile, heavy machinery, pipes, construction, packaging and household appliances. Long products include slabs, billet, rail, wire and sections, with its main markets being construction, mechanical engineering, energy and transport.

According to data from the World Steel Association, in 2016 almost 1,500 million tons of steel were manufactured, and predictions for 2017 point to continued stable consumption (with a $0.4 \%$ increase). Fig. 1 shows the production specified by geographical zones.

The steel industry directly employs more than two million people in the world, plus another two million contractors and another four million in auxiliary industries. It is a source of employment for 50 million people working in construction, transportation and energy companies. In Spain there are 22 steel production plants. In addition, there are 50 rolling and transformation facilities. Although the greatest concentration is located in the Cantabrian coast, especially Asturias and the 
Basque Country, there are factories in eleven Autonomous Communities.

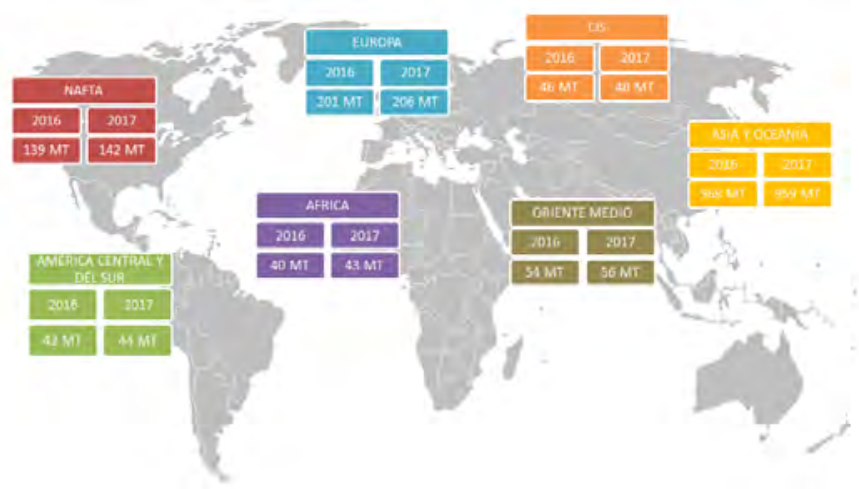

Fig. 1. World steel production in 2016 and expected in 2017 (World Steel Association).

\section{A. "non-prime" Flat Products Auctions}

In the case of the highest quality products, due to the different chemical and physical treatments inherent to the manufacturing process, and sometimes to unforeseen contingencies, not all the manufactured coils meet all the desired requirements to reach the highest level of quality, preventing its sale to the original customers. These products, denominated "non-prime" (they do not arrive at the maximum quality) are offered at first to affiliated companies and habitual clients (normally of the local region associated to each plant), or some are sent to other plants to use in alternative lines. The products of all the plants that are not sold directly are auctioned online, grouping every week the products of all the plants in Europe. If during any given number of weeks no potential customer bid for these coils or sheets, they are returned to the plant to be scrapped and reused in the process.

The auction process represents a fundamental part of the sale of products. Each week, products from all the flat products plants in Europe are auctioned online, and there are currently around 300 regular customers. Approximately 10,000 tons of steel are sold weekly through this system.

The complete product auction process encompasses the following phases:

- Preparation of the products for the auction: the products are not auctioned individually, but are previously grouped in lots ("bundles") as homogeneous as possible, with their size varying in each plant. Performing a good grouping in lots is a complex task and of great impact on the final benefit of the auction.

- Auction of the products: all products go to auction on the same day of the week at a specific time. The current auction mechanism is closed auction of first price with reserve price.

- Assigning the products to winners: after the bidding deadline, the winner of each batch is the one who made the highest bid. This bid value is compared to the reserve price that the company establishes for each batch.

The homogeneity of a lot increases its attractiveness for the bidders, propitiating an increase in the number of bids, and a potential increase in the total benefit of the auction.

\section{B. Rules for Grouping and Homogeneity in Batches}

The grouping of products in batches presents two types of characteristics: those common to the elements of a lot, and those that are used to define their homogeneity. The characteristics common to a lot allow the identification of similar products from a logical business point of view - same plant, location, shape, category, family and number of covering sides. On the other hand, to analyze the homogeneity of a lot with respect to its constituent products, the rest of the characteristics are used: -subfamily, steel grade, oiled, weight, width, thickness and coating thickness-. Sometimes, it is possible to combine products with different values of these parameters in a batch (for example, coils of different weight, different width, or with different steel grades), although it is recommended to obtain maximum homogeneity simultaneously in all the parameters.

In practice, weekly, about 3000 products are handled distributed in about 20 plants and the rules used to define the lots are the following:

- Group all the products of the different plants in lots, taking into account the obligatory characteristics common in each lot.

- Minimize the number of lots, trying each one of them to be as close as possible to its upper limit of capacity, and always complying with the restriction of minimum lot size (minimum tons for the lot to be auctionable).

- Minimize the number of products that are not included in any lot.

- Make batches as homogeneous as possible, using as parameters to measure the homogeneity: subfamily, steel grade, oiled, weight, width, thickness and coating thickness.

\section{LITERATURE REVIEW}

An auction is a market mechanism that has an explicit set of rules through which the allocation of resources and their prices is determined, based on the bids (economic valuations of the auctioned good) presented by the participants. It allows the determination of prices in a unilateral trade in a simple and practical way. There are different types of auctions, according to their defining characteristics: Direct, unidirectional, sealedbid, multi-units [3]:

The direct or reverse is focused from the point of view of the buyer or the seller. In a direct auction, buyers bid for sellers' products (they are the most common). In reverse auctions, potential sellers compete to sell goods or services to buyers.

In unidirectional auctions the auction is only carried out in one of the channels previously presented (or buyers bid or 
sellers bid), while in the case of bidirectional auctions both potential buyers and sellers bid at the same time.

With the open auctions, all bidders know the bids of others. In the case of sealed offers, participants send the offers (as a secret bid) during a pre-established period of time, after which they are evaluated according to the award criteria to decide the winner. In turn, within the sealed offers are distinguished those of only one stage (single round sealed-bid) -where potential buyers send a single bid for the product- and those of multiple stages (multi-round sealed-bid) - in which you can place bids during a predefined period, after which the bids received are published and a new bid period is opened.

Traditionally, in the unit, the bidders can only bid for one item in each auction while in the multi-unit they are allowed to bid for more than one good at a time. Multi-unit auctions are frequent, especially on the Internet, due to the availability of automatic processing of information.

These variants can be combined with each other, defining the set of final rules applicable in each case. The four most commonly used variants are the following: English, Dutch, first-price, second-price [4].

The English is an open auction with ascending bids. The item to be auctioned usually starts from a low price and potential buyers place their bids sequentially or simultaneously, until bidding is stopped. Each bidder can "hear" the offer sent by a rival bidder and has a specific time to decide whether to bid higher. Normally these auctions include a reserve price, or minimum price, that the buyer defines for the winning auction to be accepted.

However, the Dutch is an open auction with descending bids. The seller sets a high price for a certain item and the price decreases as time passes. At the moment when a bidder accepts the price by placing a bid, the auction ends and the bidder takes the item at the offered price. It is common to use this type of auction in perishable products, or also in the sale of air tickets.

In the First-price sealed-bid auction, the potential buyers are required to send their offers during a certain period of time. Offers are saved and evaluated once the bid period is over to determine the winner. The offer with the highest bid is the one that wins the product, and the amount to pay is the price of the bid.

The Second-price sealed-bid auction is similar to the first price auction, and the winner is also the bidder who makes the highest bid. However, the price to pay is that of the second highest bid.

Other variants used are: (1) Anglo-Dutch auction - mixture of the English and Dutch auction [5]; (2) Vickrey-ClarkeGroves auction, variant of the second price closed auction, aimed at auctioning a set of M items; (3) Auction wait in line, in which there is no explicit bidding process; (4) Combinatorial auction, in which the bidders make offers on several products, and specify at the same time a set of items without any of which will not buy the rest; (5) Cooperative auction, in which sellers offer price discounts based on the number of items purchased.
In the following, we analyze the studies conducted on the performance of the four most common types of auctions (English, Dutch and sealed-bids of first and second price) showing, on the one hand, comparative studies between these types, and on the other hand, studies specific on the first-price sealed-bid, which is currently the most used for the sale of steel products. As early as 1961, the Revenue equivalence theorem was postulated [6], which defines that both the English, Dutch, first price and second price auction provide the same expected value to the seller if the following conditions are met: (1) Bidders are neutral against risk; (2) Each bidder knows precisely the value of the item being bid; (3) Bidder behavior is symmetric - assumptions about other bidders and the seller are common for all bidders; (4) The final payment depends only on the bids.

If these conditions are not met, there are different studies to determine if the sealed auctions are better than the open price ones (most comparisons are made between the first price and the English auctions). In general terms, the literature shows that the sealed dominate the open price in the following scenarios: 1) when the buyers are risk sensitive [7] and 2) when there is a possibility that buyers may confabulate [8]:

There are more studies that show that the first price auction generates greater benefits than the English one both theoretically [8] and experimentally [9]. Following real studies, Miller, makes a comparison using real data at a garnishmen rate auction in Illinois concluding that the first-price sealed-bid auction gets benefits 22\% greater than English [10].

However, other authors show that, under certain conditions, not always the first-price sealed-bid auction is the most advantageous. Auctions with economic restrictions that fine those bidders that do not take the item are more beneficial than those of first-price sealed-bid [11]. Also, a comparison in an auction of farms concluding that the English auction offers a $4 \%$ higher profits for the seller than the first-price sealed-bid [12].

Another aspect to highlight in the performance of first price auctions is the so-called "the winner's curse" according to which, the winner of an auction ends up offering a bid greater than the real value of the good that is awarded. A set of parametric tests that allow measuring the severity of the winner's course was performed [13]. The logical conditions of the market are not always applicable in the world of auctions, being affected to a large extent by the winner's curse and the human behavior aware of this phenomenon [14].

\section{FACTORS TO CONSIDER IN THE DESIGN OF ONLINE AUCTIONS}

The effect of the Internet on auctions, as key advantageous elements [15]: (1) the reduction of transaction costs for buyer and seller; (2) greater accessibility for bidders and sellers; (3) greater ease in managing complex auctions and describing products. Also, it can be pointed out: (1) the ease of collecting data on the operation of auctions and (2) the possibility of a participant joining an auction while it remains open [16].

However, online auctions also have drawbacks such as the absence of contact - prior to the auction - between the auctioned object and the buyer, or potential fraud problems (the 
winner of the auction must trust the seller to send the goods). A well-designed auction should be robust in reference to assumptions about the behavior of bidders, be efficient in assigning products, have low transaction prices and be resistant to fraud. Three crucial aspects for the robust design of an online auction: the auction mechanism, its duration and restrictions on bids [17]. The use of the rank-bidding format increases buyer surplus when incumbent suppliers participate in the auction [18]

Nowadays, the English auction is the dominant one on the Internet -probably because it uses a mechanism that people find familiar and intuitive - despite its greater ease for fixing [19]. Its multi-round nature, since prices are open, increases its cost of management in the off-line context, given the need for physical presence of bidders. On the other hand, via Internet, its cost will decrease noticeably, increasing its attractiveness.

In online auctions, several parameters are often used to influence bids (e.g. restrictions on the minimum bid or reserve prices). From an analyze of 350 auctions held at SurplusAuction.com, for items available at retail sites, the authors observed that, without minimum bid, the items are auctioned with significant discounts on the sale price; however, when the minimum bid level increases, the benefit is greater (although many auctions also appear without bids) [20].

In contrast to open traditional auctions (in person), which usually last for minutes, online auctions can last for days or weeks. Thus, the duration of an online auction will influence the number of participating bidders, affecting the final result of the auction and the benefits (if the auction is too short and few bidders participate, the final price is more likely to be low).

\section{Bundling In Auctions}

This section analyzes whether the literature supports the grouping of products against their individual offer prior to the auction. The grouped sale of multiple products -bundlingusually brings benefits if their marginal costs are very low [21][22]. However, the seller waives the additional benefits that could be obtained by selling several items separately, each to the best bidder.

A seller who auctions individual items can do it simultaneously or sequentially. According to the literature, the differences in benefit between these two strategies depend on the degree of complementarity between the articles [23] [24] [25]. The benefits of sequential auctions exceed those of simultaneous auctions when the products do not complement each other, since bidders can get new information from previous auctions and bid more aggressively on successive auctions [24]. However, the authors claim that when there is complementarity between articles, simultaneous auctions tend to produce greater benefits [26]. On the other hand, the heterogeneity of products in a lot has a negative effect on the profitability of this type of auctions - in front of those of separate components-, and propose to group similar components that give homogeneity to the lot [27]. Also, the greater complementarity (or less possibility of substitution) leads to higher valuations of the lots [28].
Only a small number of articles have examined the profitability of batch auctions compared to auctions of individual components [26][29][30][31][32].

The joint analysis of these studies shows that bundling auctions are less profitable for non-complementary products; however, they are more profitable than those of separate components when there is complementarity between products.

In the case of this study, there is a high degree of complementarity between the steel products to be auctioned, so the strategy of grouping previously in lots seems clear. However, despite the higher expected profitability of composing lots of homogeneous (and complementary) products, this task entails a great operational difficulty, due to the particular characteristics of the different products. In any case, the decision to opt for a bundling methodology prior to auctions of steel products is clearly supported from the scientific point of view.

\section{CONCLUSIONS}

In this article we have analyzed the literature regarding auctions, focusing on the types currently used for the auction of steel products. The objectives of the study focused - in this context of products - on: (1) identifying the most important factors that affect the auction; (2) decide the type of auction suitable for this sector; (3) decide on the need to group products in lots - prior to the auction.

Regarding the type of auction, although under ideal conditions all offer similar returns, studies show that the closed auction of first price is better than English auction. There are studies proving that the English auction provides greater benefits but neither the sectors nor the characteristics of these studies are applied to the problem of this study. The fact that the bidders can collude with each other makes the use of a closed auction logical (supported in the same way by the literature). Similarly, the literature shows that the closed auction provides better performance when bidders are sensitive to risk. These factors prove that using a closed auction (as it is currently done) is the best option; since in addition it also avoids the appearance of bidders of last hour (opportunists).

There are no studies on auctions in the steel sector with second price; however, there is evidence that in other sectors the second price closed auction works better and provides more benefits than the first price auction [33]. To optimize the process, it is recommended to carry out a descending auction with those products that have not been sold after several weeks in the first price ascending auction. The price can go down gradually until it goes down to the scrap price. At that time the product would stop being for sale and would actually return to the plant to become scrap. In this way, it is expected to obtain greater benefits derived from good "last minute" offers to customers, who surely pay more than the scrap price.

The next step in this research will be the analyze of the bundling techniques used in the steel sector. To determine if the approach is the same regardless the firm. Also, according to previous studies, we think that some improvement can be reach in the current bundling methodology. 


\section{REFERENCES}

[1] J. Johnson, B. K. Reck, T. Wang, and T. E. Graedel, "The energy benefit of stainless steel recycling," Energy Policy, vol. 36(1), pp. 181-192, 2008

[2] K.E. Thelning, Steel and its heat treatment., s.1.:Butterworth-Heinemann, 2013.

[3] S. Parsons, J. A. Rodriguez-Aguilar, and M. Klein, "Auctions and bidding: A guide for computer scientists," ACM Computing Surveys (CSUR), vol. 43(2), pp. 10, 2011.

[4] Y. Zhang, C. Lee, D. Niyato, and P. Wang, "Auction approaches for resource allocation in wireless systems: A survey," Communications Surveys and Tutorials, IEEE, vol. 15(3), pp. 1020-1041, 2013.

[5] V. Krishna, Auction theory, s.1.:Academic press, 2019.

[6] W. Vickrey, "Counterspeculation, auctions, and competitive sealed tenders," The Journal of finance, vol. 16(1), pp. 8-37, 1961.

[7] S. Matthews, "Comparing auctions for risk averse buyers: A buyer's point of view," Econometrica: Journal of the Econometric Society, pp. 633-646, 1987.

[8] R.P. McAfee and J. McMillan, "Auctions and bidding," Journal of economic literature, vol. 25(2), pp. 699-738, 1987.

[9] J.H. Kagel and D. Levin, "Independent private value auctions: Bidder behaviour in first-, second-and third-price auctions with varying numbers of bidders," The Economic Journal, vol. 103(419), pp. 868$879,1993$.

[10] J.J. Miller, "From English to First-Price Sealed Bid: An Empirical Assessment of the Change in Auction Type on Experienced Bidders," Review of Economic Perspectives, vol. 14(2), pp. 105-127, 2014.

[11] Y.K. Che and I. Gale, "Expected revenue of all-pay auctions and firstprice sealed-bid auctions with budget constraints," Economics Letters, vol. 50(3), pp. 373-379, 1996.

[12] Y.L. Chow and J.T.L. Ooi, "First-Price Sealed-Bid Tender versus English Open Auction: Evidence from Land Auctions," Real Estate Economics, vol. 42(2), pp. 253-278, 2014.

[13] P.A. Haile, H. Hong, and M. Shum, Nonparametric tests for common values at first-price sealed-bid auctions, s.1.: s.n. 2013.

[14] J. Bulow and P. Klemperer, "Prices and the Winner's Curse," RAND journal of Economics, pp. 1-21, 2002.

[15] S. Klein, and M. O'Keefe, "The impact of the web on auctions: some empirical evidence and theoretical considerations," International Journal of Electronic Commerce, vol. 3(3), pp. 7-20, 1999.

[16] E.J. Pinker, Using transaction data for the design of sequential, multiunit, online auctions, s.1.: s.n, 2001.
[17] E.J. Pinker, A. Seidmann, and Y. Vakrat, "Managing online auctions: Current business and research issues," Management science, vol. 49(11), pp. 1457-1484, 2003

[18] S. Mithas and J.L. Jones, "Do Auction Parameters Affect Buyer Surplus in E-Auctions for Procurement?" Production and Operations Management, vol. 16(4), pp. 455-470, 2007, ISSN 10591478.

[19] P. Milgrom, "Auctions and bidding: A primer," The Journal of Economic Perspectives, vol. 3(3), pp. 3-22, 1989.

[20] Y. Vakrat and A. Seidmann, Implications of the bidders' arrival process on the design of online auctions, s.1., s.n., pp. 7--pp.,2000.

[21] T. Schoenherr and V.A. Mabert, "The use of bundling in B2B online reverse auctions," Journal of Operations Management. vol. 26(1), pp 8195,2008. ISSN 02726963

[22] Y. Bakos and E. Brynjolfsson, "Bundling and Competition on the Internet," Marketing science, vol. 19(1), pp. 63-82, 2000

[23] D.B. Hausch, "Multi-object auctions: Sequential vs. simultaneous sales," Management Science, vol. 32(12), pp. 1599-1610, 1986.

[24] P.R. Milgrom, Putting auction theory to work, s.1.:Cambridge University Press, 2004.

[25] R.W. Rosenthal and R. Wang, "Simultaneous auctions with synergies and common values," Games and economic Behavior, vol. 17(1), pp. 32$55,1996$.

[26] V. Krishna and R.W. Rosenthal, "Simultaneous auctions with synergies.", Games and economic behavior, vol. 17(1), pp. 1-31, 1996.

[27] S. Stremersch and G.J. Tellis, "Strategic bundling of products and prices A new synthesis for marketing," Journal of Marketing, vol. 66(1), pp. 55-72, 2002.

[28] R. Venkatesh and W. Kamakura, "Optimal bundling and pricing under a monopoly: Contrasting complements and substitutes from independently valued products," The Journal of business, vol. 76(2), pp. 211-231, 2003

[29] T.R. Palfrey, "Bundling decisions by a multiproduct monopolist with incomplete information," Econometrica: Journal of the Econometric Society, pp. 463-483, 1983.

[30] I. Chakraborty, "Bundling decisions for selling multiple objects," Economic Theory, vol. 13(3), pp. 723-733, 1999.

[31] R. Subramaniam and R. Venkatesh, "Optimal bundling strategies in multiobject auctions of complements or substitutes," Marketing Science, vol. 28(2), pp. 264-273, 2009.

[32] P.T.L. Popkowski Leszczyc and G. Häubl, “To bundle or not to bundle: Determinants of the profitability of multi-item auctions," Journal of Marketing, vol. 74(4), pp. 110-124, 2010.

[33] D. Lucking-Reiley, "Using field experiments to test equivalence between auction formats: Magic on the Internet," American Economic Review, pp. 1063-1080,1999. 